\title{
Editorial
}

\section{PUBLIQUE O PEREZCA ¿O PEREZCA PUBLICANDO?}

\section{Juan Carlos Villalba Cuéllar (Editor) Andrés González Serrano (Coeditor)}

Publique o perezca es el sugestivo nombre de un programa que se utiliza para medir la visibilidad de las publicaciones de autores y publicaciones con respecto al número de citaciones, conocido hoy como índice $\mathrm{H}$. Para Colciencias este es un factor importante para establecer la calidad e impacto de las publicaciones científicas y de los investigadores. Pero esa frase de "publique o perezca" que parece sentenciar algo, también entraña muchas ambigüedades en el contexto colombiano de la investigación.

Publique o perezca nos querría decir que en la actualidad el docente universitario que no investigue está condenado a no existir, y esto en el fondo guarda una finalidad plausible pero no del todo cierta. En primer lugar no todos los profesores universitarios son investigadores, es más, la mayoría no lo son, para ser investigador se necesitan competencias y aptitudes especiales que no todo educador posee, así como un contexto laboral que le permita verdaderamente hacer investigación, y esto no se cumple en un alto porcentaje de los casos.

Es raro encontrar profesores investigadores que se dediquen a hacer investigación con convicción y universidades que realmente sean conscientes de cómo se logra esto. Así que de entrada sí es muy difícil que alguien publique, es muy escaso el número de gente que perecerá en las universidades colombianas si no lo hace. Por lo tanto, la sentencia de muerte es para muy pocos.

Ahora bien, si nos centramos en el ámbito de los investigadores y su labor veremos cómo es más fácil que estos sucumban con respecto a que publiquen. Nos fundamentamos en que en próximos meses muchas de las publicaciones científicas colombianas indexadas en Publindex van a desaparecer como consecuencia de los nuevos criterios de medición. Aquí les aplicarán el "publiquen y perezcan". Los nuevos criterios se enfocan no ya en la calidad editorial sino en la visibilidad e impacto de las publicaciones.

Las universidades por su parte sufren un inmediatismo basado en los resultados, indispensables para llenar los formularios que se exigen para las acreditaciones de alta calidad y los registros calificados. Se necesitan resultados de investigación a toda costa, no importa la calidad, no importa que no formen parte de un proceso, el todo es acumular resultados, volver científico lo que no lo es, para mostrarle a los pares del Ministerio de Educación. Es así como se publican libros que reposan en librerías institucionales de universidades que ni siquiera tienen difusión, y a nadie le interesa difundir, igual no eran para eso, eran para mostrar en una visita. Los otros resultados de investigación como artículos en revistas y ponencias al ser hechos a la carrera también corren destinos similares, no fueron escritos para ser leídos o citados, porque algo que se hace a la carrera difícilmente pasará a la historia o ameritará ser citado. Dentro de esa dinámica los investigadores son instrumentalizados por las instituciones a costa de su propio prestigio. Colciencias puede tener razón en esto, muchas publicaciones científicas no son leídas ni citadas por nadie, dada su baja calidad académica.

Lo preocupante es que acabando la mayoría de las revistas no se solucionará nada, porque rellenar formularios sigue siendo la regla para las instituciones, además porque las revistas jurídicas colombianas escogen lo que publican entre lo que les llega y les llega lo que se hace 
en las universidades colombianas, entonces la calidad pareciera que se nivelara por lo bajo. Pero mirar el resultado fijándose en la calidad de las revistas además es simplista, porque detrás de la calidad de las publicaciones hay una historia y un contexto que explican muy bien por qué la baja calidad. La realidad es que entramos en un círculo vicioso, nadie cita lo que se publica porque es de baja calidad y esa calidad no depende de las revistas y a veces ni siquiera de los autores.

La consecuencia para los pocos investigadores que persisten en este opaco panorama es que tendrán que seguir investigando a las carreras, ahora juntándose con colegas de otras universidades para redactar libros que nadie lee y, en general, para cumplir a las patadas los nuevos requisitos que desconocen realidades prácticas.

Debería revisarse primero si los investigadores en verdad lo son, si los proyectos de investigación son coherentes en plazos y resultados con la calidad científica, si los sueldos son dignos para trabajar en una sola universidad para personas con formación de maestría o doctoral, si los editores y las revistas cuentan con los recursos necesarios, entre muchas otras cosas. Si dos o tres universidades lo hacen no será suficiente, porque el insumo que publican sus revistas necesariamente proviene de otras universidades.

Un segundo contexto ayudará a ejecutar la condena, los investigadores deben publicar, claro está, pero ¿qué deben publicar? A partir de ahora menos artículos y más libros u otros productos que permitan cumplir los requisitos a las universidades en el menor tiempo posible. Esto hará que muy pocos escriban en revistas indexadas y por ende que los citen.

¿Dónde deben publicar? Donde les digan, porque paradójicamente ahora el conocimiento científico solo depende del número de citaciones que uno o dos sistemas de medición de citaciones indiquen. Así que deben buscar entrar en revistas indexadas de ciertas bases internacionales que son verdaderos negocios, al investigador no le pagan por publicar ni tampoco regalías por las lecturas que hagan de sus textos, es más, a veces les cobran, y el lector abona por acceder al conocimiento.

En revistas de otros países ciertamente les tocará publicar, aunque muchas de estas no formen parte del sistema open journal. El investigador entrará en un dilema propio del contexto de ciencias sociales de alcance nacional, como el derecho: "si publico nadie me leerá y mucho menos me citará, pero la revista pertenece a esas bases que me piden”. ¿Para qué deben publicar? Los investigadores que vivan de su actividad deben sin duda cambiar la manera de publicar, en derecho es frecuente encontrar investigadores que abordan temas de investigación rebuscados, sin relevancia práctica o teóricamente repetitivos, y a partir de ahora hay que pensar en que el lector potencial de ese escrito debe consultar y ojalá citar.

Por eso es necesario saber perfilar muy bien un escrito jurídico para que sea citado, no solamente debe ser novedoso, sino tener un público amplio, debe ser sencillo para aumentar ese público destinatario, etcétera. Otro factor que perjudicará a los investigadores es que los editores de las revistas están obligados a escoger aquellos autores que tengan un índice $\mathrm{H}$ alto, así que no bastará escribir algo bueno porque un joven investigador que comienza su carrera entrará de último en la fila en una revista indexada. El círculo vicioso se completa con que nadie cita a los autores porque ya no tienen dónde publicar y donde pueden publicar muy pocos los citarán.

Estas reflexiones sugieren que la discusión frente a lo que es la investigación y lo que es científico si bien ha dado pasos adelante en el contexto colombiano está sometida a ciertas vicisitudes y paradojas que ameritan que todos los actores involucrados sigamos dialogando para mejorar nuestra realidad social. 